\title{
A Study on the Development Direction of the Jeju Trail Running Competition through the World Trail Running Competition
}

\author{
Baek Hye Kyung ${ }^{1}$ and Yoon Sang Taek ${ }^{2}$ \\ Professor, Dept. of Sports Industry, Jeju International University., Jeju-si, Jeju-do, \\ Korea \\ 1jean_78@hanmail.net, 2yoonst123@hanmail.net
}

\begin{abstract}
In this study, we will discuss an introduction to Trail Running, a new outdoor sport that has been booming around the world recently, the status of trail running around the world, and the direction of development of trail running with Jeju. I think it's time for Jeju to have new sports products in line with the changing world trend. The Jeju provincial government also needs to make efforts to develop the world's most prestigious trail running competition, such as France and Ultra-Trail Montblanc, into a trail running competition that can represent Asia, taking advantage of the beauty and regional characteristics that only Jeju has, such as the Boston, New York Marathon, Berlin and London Marathon. Also, I believe that increasing the level of interest in trail running through various discussions and academic interests can serve as an opportunity to develop trail running in Korea.
\end{abstract}

Keywords: Jeju island, Trail running competition, Regional economic revitalization, Tourism industry, Sports industry

\section{Introduction}

Jeju's nature has such a beautiful natural environment that it is listed as a UNESCO World Heritage site, while the courses of Mt. Halla, Oreum, and Ollegil boast the best trail running course ever compared to any other competition in the world. As such, the conditions are optimal for holding a worldwide popular trail-running event [1]. Local governments have recognized the sport as a cultural tourism event and increase the practice of promoting local development strategies to hold sporting events [2].

Jeju Special Self-Governing Province is also trying to create a new image that combines the island of sports from the island of tourism and recreation, and Jeju Island is highlighting the image of a sports mecca. In particular, by attracting a large-scale sporting event business, which is a pollution-free value-added industry, it plans to foster it as a major strategic business in the 21 st century in connection with the tourism industry [3]. The effect of sporting events on the local economy has become a major concern of local governments, and the research on economic ripple effects through sporting events is being actively conducted.

Sports events bring about the effects of inducing local employment and production through the promotion of the sports tourism industry in the host region, increasing the income of local residents, activating the local tourism industry and indirect capital investment, and developing

Article history:

Received (March 19, 2019), Review Result (June 21, 2019), Accepted (July 24, 2019) 
the region [4]. In addition to economic growth, the sports industry has intangible benefits such as stress relief, health maintenance, and social ties in addition to economic values such as the growth of the sports industry, job creation, and tourism resource development. It is growing into a high value-added industry that provides the benefits of deriving and expanding the base of sports promotion by market. In particular, the cultural, tourism, and leisure sports business is a high value-added industry that can generate high profits at a low cost with creative ideas, and is considered to be the next generation growth engine that causes production in other fields.

Therefore, in this study, we will discuss an introduction to Trail Running, a new outdoor sport that has been booming around the world recently, the status of the world's trail running, and the development direction of trail running with Jeju.

\section{Status of trail running in the world}

\subsection{Status of other countries}

\subsubsection{Europe}

Europe is a paradise for trail-running, and the trail-running market is so active. Away from the best trail courses and cities, including the Alps, the quiet and beautiful rural landscape is a trail-running course, a popular sport that anyone can enjoy regardless of age, gender or location. France's UTMB Ultra-Trail du Mont-Blanc, the world's largest, started in early 2000 and is now the most famous race with 7,000 participants from more than 70 countries around the world.

\subsubsection{America}

The U.S. is second only to the European region to the trail-running population. There are more than 6 million people in the U.S. alone, and hundreds of large and small trail-running competitions will be held. Trail running ranges from light running to adventure racing in extreme conditions. The most famous Ultra Trail Race in the U.S. is 'The Western States Endurance 100 Mile Run' in western California.

\subsubsection{Africa}

In Africa, many desert marathon races are held every year. There is the Sahara Desert Marathon in Morocco, the Sahara Desert Marathon in Egypt, the Namibia Desert Marathon, the Kalahari Desert Marathon, and so on. Many new competitions are being created in remote African mountains, jungles, and most of them are held in European or American companies.

\subsubsection{Asia}

Last year, in the second year of the competition, more than 1,000 athletes participated. In addition, there are many new trail-running competitions in Asia, including China, Hong Kong, Singapore, Taiwan, the Philippines, and others, and the spring of trail-running is continuing around the world.

\subsection{Status of our country}

Participants rated the beauty of Jeju's nature, which they could not feel when they participated in the existing road marathon, and the "power of nature" they felt while running in 
nature as the biggest attraction. There are $10 \mathrm{~km}$ and $5 \mathrm{~km}$ courses, and it is currently the mostwatched competition in Korea by foreigners.

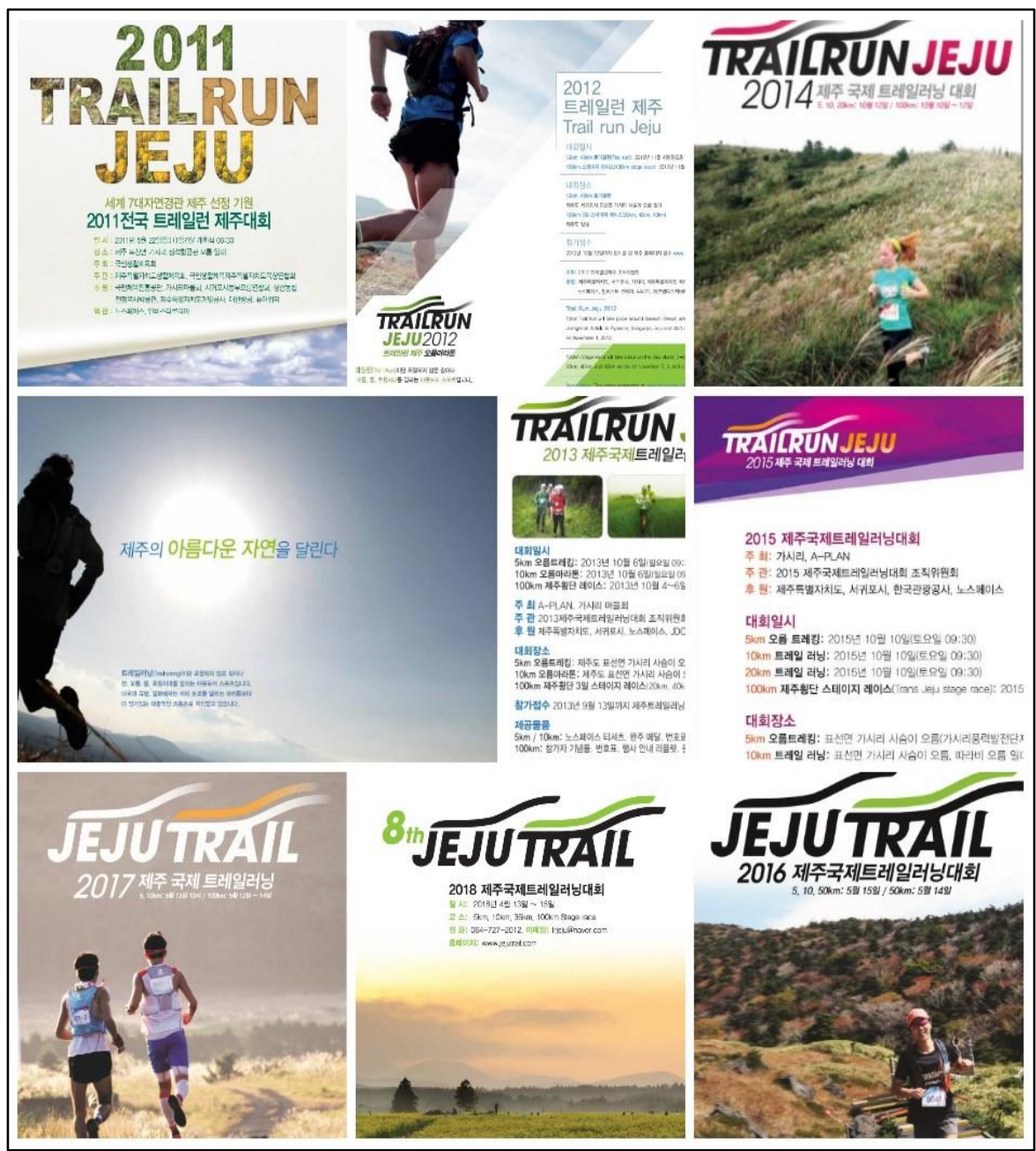

Figure 1. 2011-2018 Foster of jeju trail running competition

\subsection{The status and ripple effects of the world's trail running}

Table 1. Famous ultra trail running status for each continent

\begin{tabular}{cc}
\hline & competition \\
\hline & -FishRiverCanyonUltra Marathon(Namibia) \\
(Africa) & -Kalahari Augrabies Extreme Marathon 250km \\
& -Peninsula Ultra Fun Run 80km \\
-Rhodes Trail Run
\end{tabular}




\begin{tabular}{|c|c|}
\hline \multirow{5}{*}{ (Asia) } & -Trans Japan Alps Race 415km(since 2002) \\
\hline & -Tsuneo Hasegawa Gup Japan Mountain Endurance Race \\
\hline & $71.5 \mathrm{~km}($ since 1993$)$ \\
\hline & -Ultra-Trail Mount Fuji (UTMF):161km(since 2011) \\
\hline & -Trail Run Jeju(korea) 100km(since 2011) \\
\hline \multirow{8}{*}{ (Europe) } & -Grande Trail serra d' Arga: 45 kilometres (28 mi) \\
\hline & -Madeira Island Ultra Trail 116km \\
\hline & -Transvulcania $83 \mathrm{~km}$ \\
\hline & -Ultra-Trail du Mont-blanc 166km \\
\hline & -Ultra Trail serra da freita: 65 Kilometres ( $40 \mathrm{mi}$ ) \\
\hline & -Ultra Trail Geira Romana: 53 Kilometres (32 mi) \\
\hline & -Ultra Trail Amigos da Montanha: 62 Kilometres (39 mi) \\
\hline & -Trans Alpine-run 300km(8 stage) \\
\hline \multirow{6}{*}{ (America) } & -Badwater Ultramarathon $217 \mathrm{~km}$ \\
\hline & -Bear 100 Mile Endurance Run: 100 miles (160 km) \\
\hline & -Hardrock Hundred Mile Endurance Run 160km \\
\hline & -Leadville Trail $160 \mathrm{~km}$ \\
\hline & -Mogollon Monster $171 \mathrm{~km}$ \\
\hline & -Western States Endurance Run 160km \\
\hline \multirow{2}{*}{ (Oceania) } & -Kepler Challenge New Zealand) 60km \\
\hline & -Kokoda Challenge Race 96km \\
\hline
\end{tabular}

\section{A study on the development of the trail-running contest in jeju-do}

\subsection{Administrative and financial support plan for the trail running competition}

The Jeju International Trailing Competition is a meaningful sports event considering regional characteristics [5]. However, the initial stage of the trailer park is the lack of interest and support from local residents and local governments. Therefore, it is necessary for local residents and local governments to provide administrative and financial support for the trailer park to grow into a traditional competition unique to Jeju Island, as well as to pass sponsorships with Samdasu and Outdoor companies. 


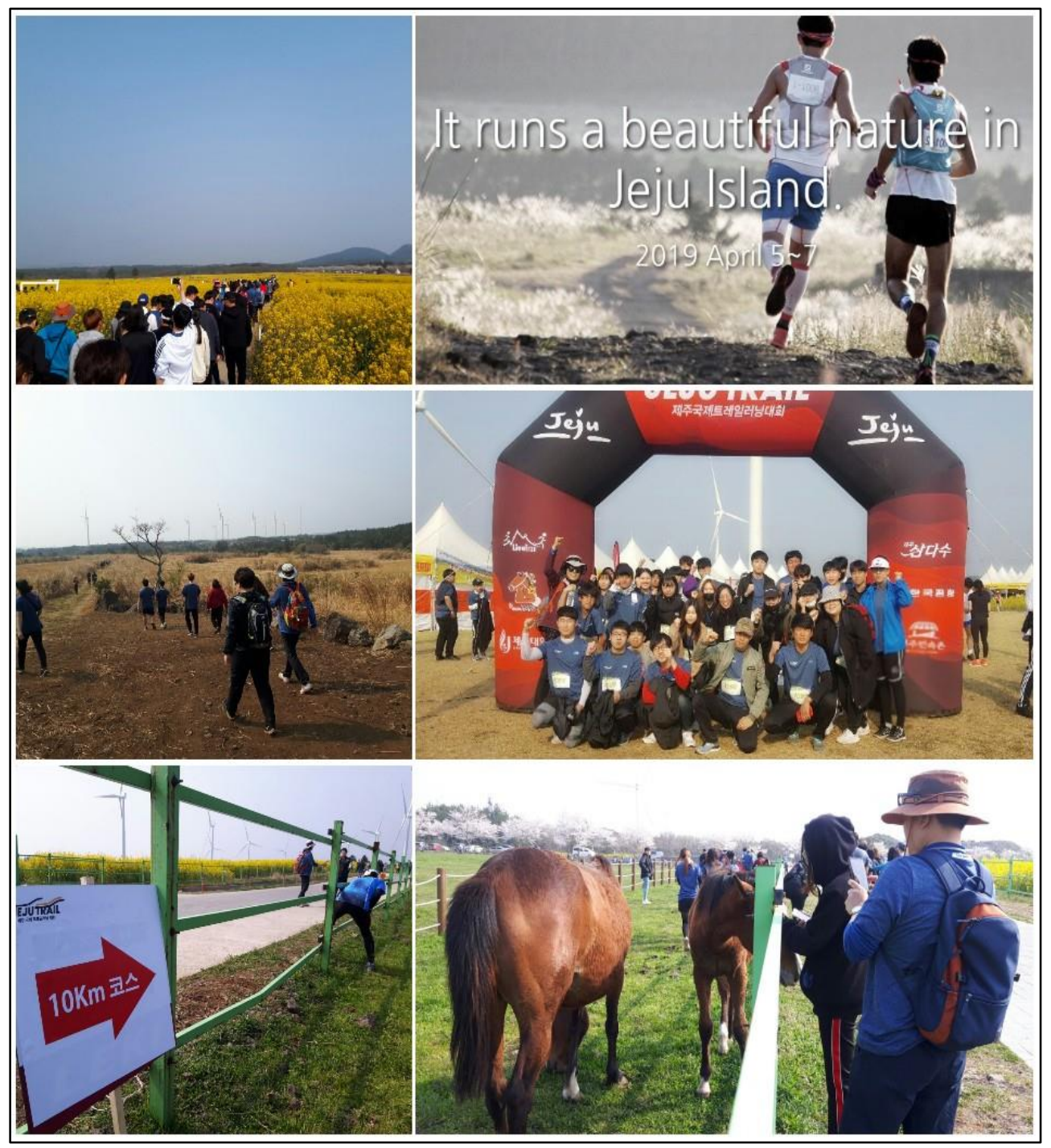

Figure 2. 2019 Jeju trail running competition

\section{Conclusion and implications}

Due to the high degree of industrialization, urban residents are under various stresses. As a result, urban residents are increasingly subjected to industrial stress and adversely affect their health, thereby increasing their desire for active and interesting leisure sports tourism as a way to maintain their physical and physical health. This phenomenon is specialized in conjunction with the recent well-being of tourism [6]. Recently, the demand for leisure sports has soared and the perception of this has changed, leading to the participation of advanced sports. In addition to new leisure sports, outdoor markets such as camping and trekking are growing every year.

According to this trend, if the trail running competition, a new outdoor sport with nature, is made into a sports tourism product representing Jeju Island, it is expected to succeed as another 
tourism product following the Olle trail where the beautiful nature and sports events of Jeju are well-matched.

As a result, Jeju needs new sports products to keep up with the changing world trend The Jeju provincial government also needs to make efforts to develop the world's most prestigious trail running competition, such as France and Ultra-Trail Montblanc, into a trail running competition that can represent Asia, by taking advantage of the beauty and regional characteristics that only Jeju has, such as the Boston, New York Marathon, Berlin and London Marathon. In addition, increasing interest in trail running through academic interests and various discussions may be an opportunity for trail learning to develop in Korea.

\section{References}

[1] S. H. Kang, "The roles of festival service quality affecting relation quality and visitors' long-term relationship orientation," Korean Journal of Local Government and Administration Studies, vol.29, no.4, pp.423-441, (2015)

[2] E. Y. Choi and W. J. Cho, "Analyses of demand and consumption expenditure determinants for activation of marine sports,” Korean Journal of Sport Management, vol.22, no.22, pp.19-31, (2017)

[3] B. S. Kim, H, K. Beak, and M. H. Yang, "Qualitative content analysis on participation constraints and discontinuation reasons for horseback riding among horseback riding club members of jeju province," Korean Journal of Leisure, Recreation \& Park, vol.40, no.1, pp.48-68, (2016)

[4] W. J. Joe and S. B. Kang, "Analyses of sustainability (TBL) of marine sport events," Journal of Navigation and Port Research, vol.37, no.1, pp.91-100, (2013) DOI: 10.5394/KINPR.2013.37.1.91

[5] M. C. Kim and D. H. Lee, "An analysis of the relationship among local people's recognition of the effectiveness of sports industry policy, local government's management evaluation elements, and regional competitiveness : focusing on the jeju special autonomous province," Journal of Sport and Leisure Studies, vol.0, no.1, pp.235247, (2015)

[6] O. L. Park and B. Y. Moon, "The effect of leisure sports festival flow on tourist's satisfaction and recommendation intention," Journal of Convergence Tourism Contents, vol.5, no.1, pp.29-39, (2019) 